\title{
Current Status of Multiple Drug Molecules, and Vaccines: An Update in SARS-CoV-2 Therapeutics
}

\author{
Ramesh Kandimalla ${ }^{1,2} \cdot$ Albin John $^{3} \cdot$ Chandrika Abburi $^{4} \cdot$ Jayalakshmi Vallamkondu ${ }^{5} \cdot$ P. Hemachandra Reddy ${ }^{6,7,8,9}$
}

Received: 2 June 2020 / Accepted: 8 July 2020 / Published online: 15 July 2020

(C) Springer Science+Business Media, LLC, part of Springer Nature 2020

\begin{abstract}
The coronavirus disease of 2019 (COVID-19) is a pandemic disease that has taken the lives of many around the world. It is caused by severe acute respiratory syndrome-corona virus-2 (SARS-CoV-2). To date, the USA, Italy, Spain, France, Russia, and the UK have been hit the hardest by the virus. However, death counts are still rising. Some nations have managed to "flatten" the death rate via protective measures such physical distancing, quarantine measures, and therapeutic management. The structure of the SARS-CoV-2 virus comprises of S proteins, M proteins, E proteins, hemagglutinin esterases, nucleocapsid proteins, and a 30kb RNA genome. Viral proteases cleave these polyproteins and RNA-dependent polymerases replicate the genome. Currently, there are no effective therapies against this new disease. Numerous investigators are developing novel protease inhibitors, some of which have made it into clinical trials. Researchers are also attempting to develop a vaccine. In this review paper, we discuss the latest therapeutic developments against COVID-19.
\end{abstract}

Keywords SARS-CoV-2 $\cdot$ HCQ $\cdot$ Remdesivir $\cdot$ Protease inhibitor $\cdot$ Vaccines

\section{Introduction}

In 2019, the globe witnessed the birth of a new respiratory system disease caused by a novel coronavirus, severe acute respiratory syndrome coronavirus type-2 (SARS-CoV-2) [1]. The World Health Organization (WHO) named the respiratory disease as novel coronavirus disease discovered in 2019 (COVID-19). On March 11, 2020, it was declared a pandemic disease. The world was crippled by the virus due to a lack of health infrastructure and preparedness.

Population genetic analysis revealed that there were two variants of the SARS-CoV-2, L and S. Between the "L"

P. Hemachandra Reddy

hemachandra.reddy@ttuhsc.edu

1 Department of Biochemistry, Kakatiya Medical College, Warangal, Telangana 506007, India

2 Applied Biology, CSIR-Indian Institute of Technology, Uppal Road, Tarnaka, Hyderabad, Telangana 500007, India

3 Internal Medicine, Texas Tech University Health Sciences Center, Lubbock, TX, USA

4 University of Chicago, Chicago, IL 60637, USA

5 National Institute of Technology, Warangal, Telangana 506004, India
(70\%) and "S" (30\%) type variants of SARS-CoV-2, the L type had a high transmission rate [2]. The reservoirs for these viruses are camels, civet cats, camels, cattle, and bats. COVID-19 infected patients have a variety of symptoms including cough, fever, headache, chills, shortness of breathing, muscle pain, sore throat, and even a loss of taste and smell [1]. The SARS-CoV-2 enters into the alveolar type 2 cells (AT2 cells) through the angiotensin-converting enzyme-2 (ACE-2) receptor and causes pneumonia, emphysema, and chronic bronchitis. The ACE-2 has a receptor-binding domain (RBD) for the spike proteins of SARS-CoV-2. When the disease advances, it leads to multi-organ failure and even death

6 Internal Medicine, Neuroscience \& Pharmacology, Texas Tech University Health Sciences Center, Lubbock, TX, USA

7 Neurology, Departments of School of Medicine, Texas Tech University Health Sciences Center, Lubbock, TX, USA

8 Public Health Department of Graduate School of Biomedical Sciences, Texas Tech University Health Sciences Center, Lubbock, TX, USA

9 Department of Speech, Language and Hearing Sciences, School Health Professions, Texas Tech University Health Sciences Center, Lubbock, TX, USA 
[3]. SARS-CoV-2 has a reproductive number (R0) which is 2.2. In other words, one SARS-CoV-2 infected patient may infect and transmit approximately to 2.2 new individuals. The virus has an average incubation period of 5.8 days. The highest case fatality rate is seen in the USA, Italy, Spain, France, and the UK (https://covid19.who.int/). Currently, there is no accurate therapy against SARS-CoV-2, but researchers across the globe are developing different drug molecules and vaccines.

The genome and protein sequences of COVID-19 virus was identified and confirmed after comparing it with other coronaviruses of pangolins, bats, cats, and camels $[4,5]$. The genetic architecture of SARS-CoV-2 is almost similar to that of SARS-CoV and MERS-CoV. SARS-CoV and MERS$\mathrm{CoV}$ are coronaviruses that caused respiratory disease outbreaks in 2003 and 2012 respectively. The genome of SARS-CoV-2 originated in China and has pp1ab, pp1a polyproteins, and codes for protein phosphatases. The orflab of RNA is the largest gene in the genome and encodes for the pplab protein. It contains nsp1-nsp10 and nsp12-nsp16 (15 nsps). Orflab also encodes the ppla protein that contains nsp1-nsp10 (10 nsps) [4]. Structural proteins are encoded by four structural genes including spike (S), envelope (E), membrane $(\mathrm{M})$, and nucleocapsid $(\mathrm{N})$ genes [5]. In addition, SARS-CoV-2 has a unique polybasic cleavage sequence and an O-linked glycan's sequence.

The genome structure of SARS-CoV-2 offers multiple targets for drug molecules that can be used in COVID-19 therapy. Studying gene function in silico, investigators across the world are targeting proteases, ACE-2, hemagglutinin esterase (HE), E proteins, and RNA-dependent polymerases actions. Vaccine development has also begun in parallel. The vaccines are being developed by inactivating or attenuating the SARSCoV-2 (whole or a piece). Almost 150 vaccine types in almost 1000 clinical trials are being explored worldwide. In this review paper, we describe the clinical status of different therapeutic interventions, both novel and repurposed, to the combat SARS-CoV-2 pandemic disease.

\section{Promising Repurposed Drug Molecules for SARS-CoV- 2}

\section{Hydroxychloroquine}

In COVID-19 patients, it is observed excessive production of cytokines and interferons and cause inflammation. Chloroquine diphosphate (CQ) and hydroxychloroquine (HCQ) are used for the treatment of malaria, systemic lupus erythematosus, and rheumatoid diseases and are attributed to the anti-inflammatory effect on IL-6, IL-17, and IL-22 cytokines. HCQ acts on the ACE2 receptor and prevents viral entry by inhibiting its interaction with spike glycoprotein-ganglioside. Besides, it also alters endosomal and lysosomal activities. HCQ exerts its therapeutic actions by reducing acidification of endosomes and attenuation of host receptors glycosylation, proteolytic processing, cytokine production, and lysosomal activity, autophagy, and endocytic pathways. It is widely believed that HCQ might have multiple therapeutic mechanisms and it may vary depends on pathogens. HCQ enhances intracellular $\mathrm{pH}$ and inhibits the lysosomal activity of antigen-presenting cells (APCs), eventually affects the cathepsins, MAP kinase, and autophagosomal functions, and eventually causes the structural damage to the spike proteins of SARS-CoV-2 [6-13] (Figs. 1 and 2) (Table 1). In addition, HCQ and CQ can also attenuate cytokine production, lysosomal activity, and autophagy $[14,15]$. Initially, clinical evidence of HCQ and CQ in SARS-CoV-2 has not been published yet but media outlets from China have alleged that these drugs can help reduce disease progression, increase viral load clearance, and improve pulmonary damage in more than 100 patients [16].

Another unrandomized clinical study findings in $36 \mathrm{pa}-$ tients (control $N, 16$; HCQ-treated patients $N, 20$ ) revealed that HCQ (200 mg, TID, 10 days) along with azithromycin (500 $\mathrm{mg}$ on day $1,250 \mathrm{mg} /$ day for 4 days) showed reduced SARS-CoV-2 viral load and these observations were confirmed by real-time RT-PCR assay [17]. In another randomized study, $86.7 \%$ of subjects have shown negative with nucleic acid test and 33.3\% of HCQ-treated group has shown improvements on CT images related to pneumonia with HCQ (400 mg/day, 5 day, and conventional treatments) [18]. Imperatively USFDA authorized physicians to use HCQ for the treatment of COVID-19 patients in the USA [19]. Furthermore, in 21 COVID-19-positive organ transplant recipients at Houston Methodist J.C. Walter Jr. Transplant Center with co-morbidities such as diabetes mellitus, hypertension, and coronary artery disease, 11 patients received a combination therapy of azithromycin and hydroxychloroquine. Only one patient from this cohort has expired [20].

Dosages of HCQ vary. Certain guidelines suggest a dosage of $400 \mathrm{mg}$ twice a day that then transitions to two doses of 200 mg per day [21]. Indian Council of Medical Research scientists, in India, recommended asymptomatic health workers an HCQ regiment of $400 \mathrm{mg}$ twice a day for the first week, and then a $400 \mathrm{mg}$ dose per day for 7 weeks (https:// icmr.nic.in/sites/default/files/upload_documents/HCQ Recommendatio n_22March_final_MM_V2.pdf). HCQ and CQ can cause retinopathy and prolonged QTc (with fatal arrhythmias-tachycardia) [22, 23]. It is considered safe in pregnant women and has not shown any ocular toxicity in infants [24].

In 2020, Borba et al. undertook a randomized clinical trial study (RCT) (NCT04323527) to investigate the safety and efficacy of (high and low dose) CQ on hospitalized SARSCoV-2 patients. In this phase IIb study, patients were 


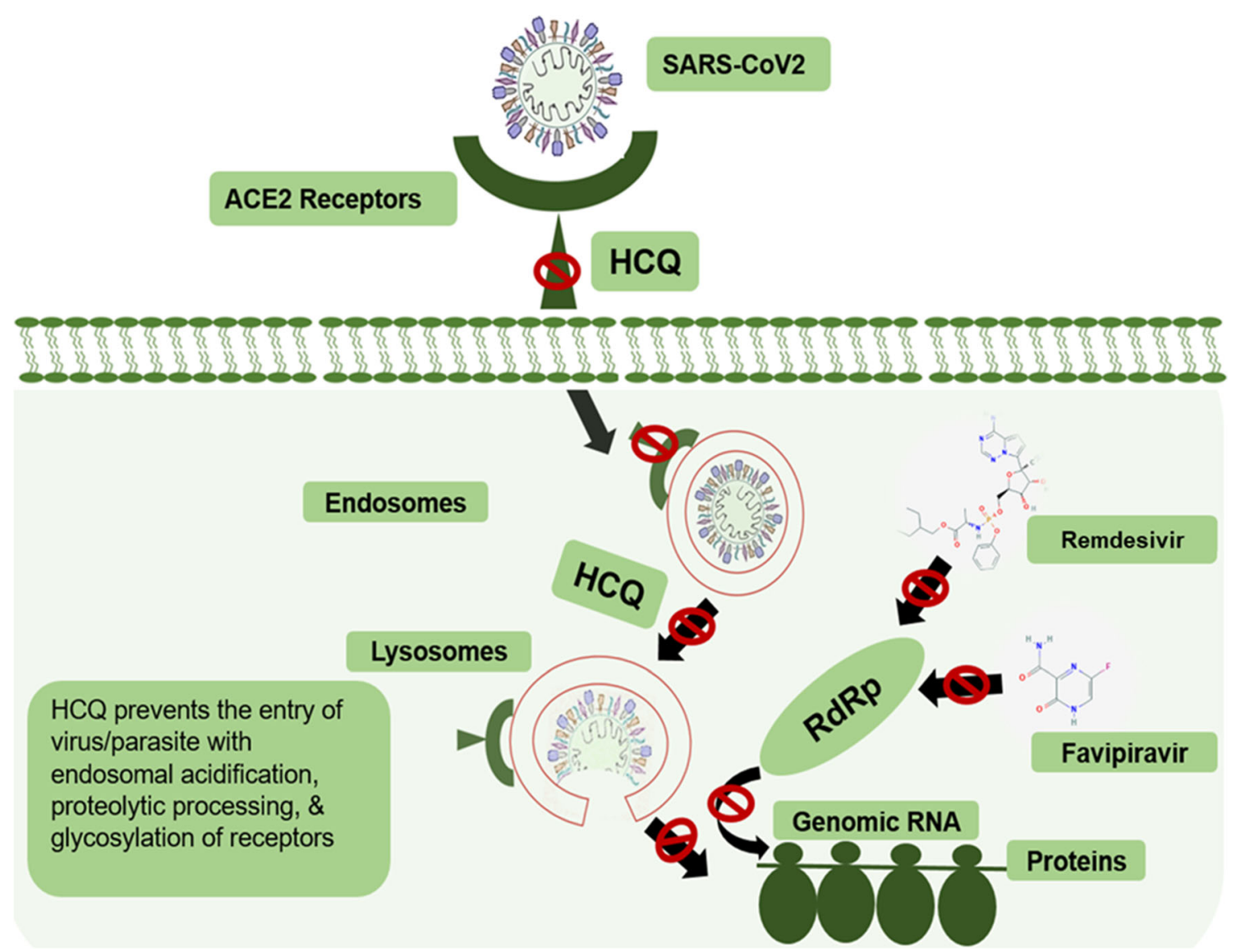

Fig. 1 Mechanism of action of HCQ, remdesivir, and favipiravir to exacerbate COVID-19: SARS-CoV2 enters into the host cell (AT2) through ACE2 receptors and under goes subsequent stages in endosomes and lysosomes and finally with the help of RNA-dependent polymerase undergoes replication and produces polyproteins (S, M, E, N). HCQ exerts its action at different levels: prevents the entry of SARS-CoV2 into the host cell, glycosylation of host receptors, endosomal acidification, and proteolytic processing. Remdesivir and favipiravir act on RNAdependent RNA polymerase ( $\mathrm{RdRp}$ ) to prevent replication and translation processes segregated into high and low-dose group in a 1:1 ratio. Highdose group patients $(N, 40)$ were given $600 \mathrm{mg}$ CQ tablets
$(150 \mathrm{mg} \times 4)$ twice a day for 10 days and low-dose group patients $(N, 41)$ were given $450 \mathrm{mg}$ CQ twice a day. On day 0 ,

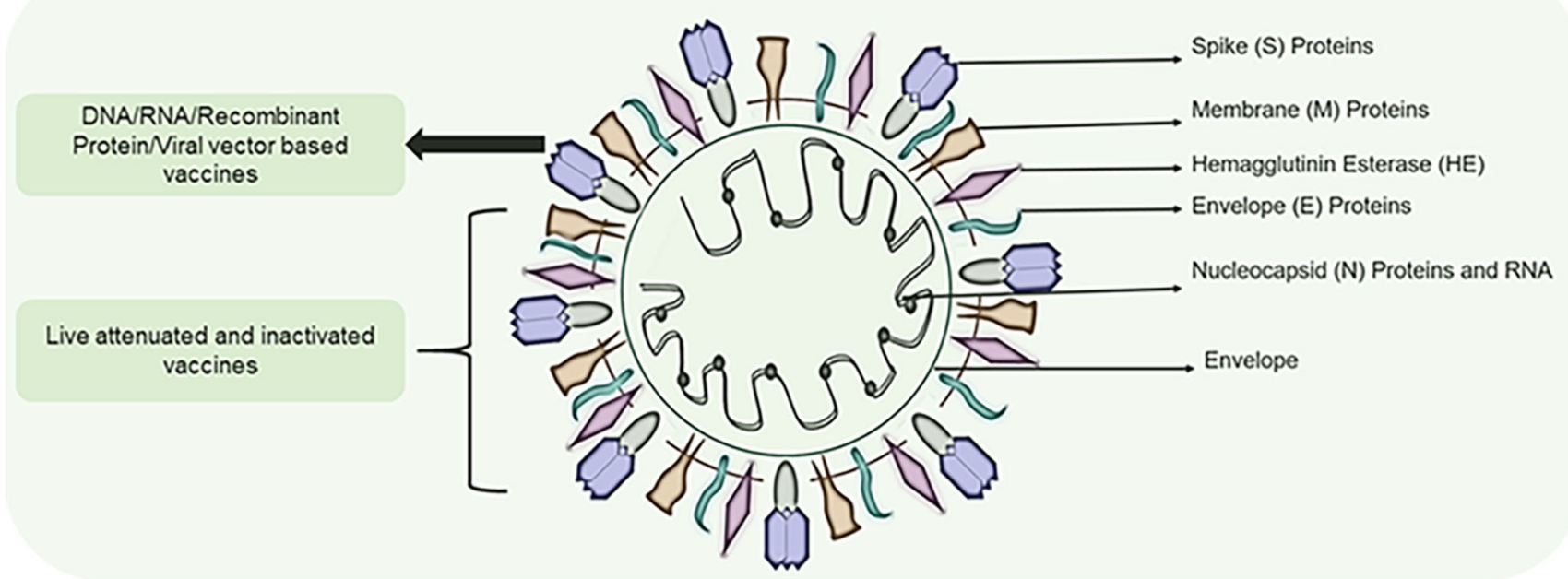

Fig. 2 Structure of SARS-CoV2: it depicts spike (S), membrane (M), envelope (E), nucleocapsid (N), and hemagglutinin esterase (HE) and targets for vaccines and drug molecules 
Table 1 Repurposing drugs for COVID-19

\begin{tabular}{|c|c|c|c|c|}
\hline Drug Molecule & Mechanism of action & $\begin{array}{l}\text { Route of } \\
\text { administration }\end{array}$ & $\begin{array}{l}\text { Primary license } \\
\text { for }\end{array}$ & Proposed dose for COVID-19 \\
\hline Chloroquine & Polymerase inhibitor of heme & $\begin{array}{l}\text { Injectable } \\
\text { or oral }\end{array}$ & Malaria & Hydroxychloroquine $400 \mathrm{mg}$ per day for 5 days \\
\hline $\begin{array}{r}\text { Ritonavir }+ \\
\text { lopinavir } \\
\text { (Kaletra) }\end{array}$ & Protease inhibitors & Oral & HIV infection & $500 \mathrm{mg}$ once, twice a day, 2 weeks \\
\hline $\begin{array}{l}\text { Ribavirin }+ \\
\text { ritonavir }+ \\
\text { lopinavir }\end{array}$ & Nucleoside and protease inhibitors & Oral & $\begin{array}{l}\text { SARS-CoV and } \\
\text { MERS-CoV } \\
\text { infection, } \\
\text { HIV }\end{array}$ & $\begin{array}{l}\text { Clinical trial: (1) lopinavir } 400 \mathrm{mg} / \text { ritonavir } 100 \mathrm{mg} \\
\mathrm{BID} \text {, plus (2) ribavirin } 2.4 \mathrm{~g} \text { orally as a loading dose } \\
\text { followed by } 1.2 \mathrm{~g} \text { orally every } 12 \mathrm{~h} \text {. Duration of } \\
\text { treatment is up to } 10 \text { days. } \\
\text { Case study: ribavirin } 600 \mathrm{mg} 2 \times \text { day and lopinavir + } \\
\text { ritonavir } 1000 \mathrm{mg} 1 \times \text { day }\end{array}$ \\
\hline Darunavir/cobicistat & Protease inhibitors & Oral & HIV infection & Darunavir $800 \mathrm{mg}$ and cobicistat $150 \mathrm{mg}$ QID \\
\hline $\begin{array}{l}\text { Arbidol } \\
\quad \text { (umifenovir) }\end{array}$ & $\begin{array}{l}\text { Targets S protein and ACE2 } \\
\text { interaction causes inhibition of } \\
\text { membrane fusion of the viral } \\
\text { envelope }\end{array}$ & Oral & $\begin{array}{l}\text { Influenza } \\
\text { infection }\end{array}$ & Arbidol tablets $200 \mathrm{mg}$ QID \\
\hline Remdesivir & $\begin{array}{l}\text { Nucleoside inhibitor and mitigates } \\
\text { RNA polymerase activity and } \\
\text { prevents viral replication }\end{array}$ & IV & $\begin{array}{l}\text { Ebola and } \\
\text { corona family } \\
\text { virus } \\
\text { infection }\end{array}$ & $\begin{array}{l}200 \mathrm{mg} \text { loading dose on first day, followed by } 100 \\
\text { mg iv once - daily maintenance doses for } 9 \text { days. }\end{array}$ \\
\hline Camostat & $\begin{array}{l}\text { TMPRSS } 2 \text { of host serine protease } \\
\text { inhibitor }\end{array}$ & Oral & $\begin{array}{l}\text { Pancreatitis and } \\
\text { coronaviruses } \\
\text { infection }\end{array}$ & NA \\
\hline
\end{tabular}

the dosage was $3 \times 150 \mathrm{mg}$ and 1 placebo tablet. The placebo tablets were given for 4 days; then from day 5 to 9,4 placebo tablets were given twice a day. In addition to $C Q$, patients were treated with $1 \mathrm{~g}$ ceftriaxone twice a day for 7 days, and $500 \mathrm{mg}$ of azithromycin per day for 5 days. To prevent an influenza infection, participants were also treated with $75 \mathrm{mg}$ of oseltamivir (neuraminidase inhibitor) twice a day for the first 5 days. Viral RNA was detected in 31 patients of both groups; high-dose groups had a higher fatality rate (39\%) than low-dose groups (15\%). Based on the QTc intervals, CK-MB levels, $\mathrm{Hb}$ levels, and fatality rate, authors have suggested that a high dosage of CQ is not safe to critically ill patients. Conclusions from this study cannot be extrapolated to nonsevere patients. Low-dosage CQ may be advisable to mitigate COVID-19 infection [25].

There has been increased research into the role of HCQ and CQ as possible treatments for COVID-19. Shanghai Public Health Clinical Center, China, registered a $\mathrm{RCT}$ (NCT04261517) titled "Efficacy and Safety of Hydroxychloroquine for Treatment of COVID-19" that had 30 participants and is now in phase 3 . The patients who were diagnosed with COVID-19 pneumonia were included. Participants were above the age of 18. Pregnant women and patients with chronic diseases (lung, heart, liver, and kidney, brain, and blood diseases) were excluded in this trial. Patients who had hearing loss, retinopathy, and hypersensitivity due to HCQ were also excluded from the study (https:/clinicaltrials. gov/ct2/show/NCT04261517). The University of Oxford also registered an interventional, double-masked $\mathrm{RCT}$ (NCT04303507) that is now in its pre-clinical stage. This study looked at effects of treatment of symptomatic COVID19 patients with HCQ. Patients had renal disease and retinal loss; prolonged QT syndrome patients, individuals who had hypersensitivity reactions, those who could not receive CQ, and individuals who are already taking CQ and HCQ are not included in this study (https://clinicaltrials.gov/ct2/history/ NCT04303507?V_2=View\#StudyPageTop). As more results come from clinical trials of this drug, researchers and physicians can learn more about the effects of HCQ, both therapeutic and detrimental, in COVID-19 patient care. Further study has to be conducted to understand the drug's efficacy and safety.

\section{Ribavirin}

A guanine nucleoside analogue, ribavirin prevents viral replication by acting on RNA-dependent RNA polymerase (RdRp) (Fig. 2, Table 1). There are no clinical studies or published data on the therapeutic benefits of this analogue on COVID-19. Adverse effects such as hepatotoxicity and blood diseases have been noted in SARS-CoV patients treated with this analogue. Ribavirin, when used with interferon, did show very mild therapeutic benefits against MERS-CoV infection [26]. Further study of ribavirin in SARS-CoV-2 needs to be done. 


\section{Lopinavir-Ritonavir}

The lopinavir and ritonavir combination was the first USFDAapproved drug therapy for HIV. They may act as protease inhibitors for 3-chymotrypsin protease (Fig. 2, Table 1) in the novel coronaviruses infection. Past clinical studies of this drug as a therapy for SARS-CoV and MERS-CoV infections have shown mild improvements. However, there has not been as much information of drug efficacy on SARS-CoV-2 [27-29]. In 2020, Cao et al. conducted a RCT (registered with Chinese clinical trials, ChiCTR2000029308) on COVID-19 patients. In this study, 199 confirmed COVID-19 patients were divided into the control group (100 patients) and the experimental group (99 patients). Those who had hypersensitivity reactions, allergy to this drug combination, and liver cirrhosis were excluded from this study. The eligible patients were treated with lopinavir-ritonavir (400 mg:100 mg), BID, for 14 days. Normally, this drug combination causes diarrhea, nausea, hepatotoxicity, and distress in the intestine. In this RCT, $50 \%$ of patients were shown to have drug combination-related side effects. The drug combination did not show any therapeutic benefits for COVID-19 patients [31].

\section{Darunavir and Cobicistat}

The darunavir and cobicistat drug combination is a USFDAapproved drug combination for HIV and acts as anti-retroviral agents. Cobicistat (CBI) is a protease inhibitor for cytochrome P450 3A and darunavir is an inhibitor of HIV protease (Fig. 2, Table 1). However, it lacks clinical evidence in treating COVID-19 patients [32]. However, one recent study has shown non-anti-viral may help combat SARS-CoV-2 in Caco- 2 cells with $\mathrm{EC}_{50}>100 \mu \mathrm{M}$. There is a RCT in phase III in China (registration number NCT04252274) for the treatment of COVID-19 with darunavir $(800 \mathrm{mg}) /$ cobicistat (150 mg) QID (https://clinicaltrials.gov/ct2/history/ NCT04252274?A=1\&B=3\&C=merged\#StudyPaeTop).

\section{Combination Therapies}

There are a few trials that are investigating protease inhibitor combinations and nucleoside analogues/or interferons: ribavirin + ritonavir + lopinavir, lopinavir + ritonavir + IFN + ribavirin, and lopinavir + ritonavir + IFN $\beta 1 \mathrm{~b}$. The proposed dosages for ribavirin + ritonavir + lopinavir drug combination is lopinavir $400 \mathrm{mg}$, ritonavir $100 \mathrm{mg} \mathrm{BID}$, and ribavirin, $2.4 \mathrm{~g}$ of which is given orally as a loading dose and after the loading dose, $1.2 \mathrm{~g}$ of ribavirin is given orally every $12 \mathrm{~h}$ for 10 days [33].

\section{Favipiravir}

Favipiravir is a purine nucleotide that inhibits viral replication by inhibiting RNA polymerase activity. It is also known as T-
705 or favipiravir ribofuranosyl-5'-triphosphate (Figs. 1 and 2, Table 1). It has shown anti-viral activity against various RNA viruses (Influenza, H1N1, Ebola, etc.). The recent in vitro study demonstrated anti-viral activity $\left(\mathrm{EC}_{50}-61.88 \mu \mathrm{M} / \mathrm{L}\right)$ against COVID-19 in Vero E6 cells [34]. The half-life of favipiravir is $5 \mathrm{~h}$. Higher dosage can be recommended against SARS-CoV-2 based on the previous lower $\mathrm{EC}_{50}$ values against Ebola and influenza infection. Some studies tried dosages ranging from 2400 to $3000 \mathrm{mg}$ BID for every $12 \mathrm{~h}$ and maintenance dosage from 1200 to $1800 \mathrm{mg}$ for every $12 \mathrm{~h}$. It is an available treatment in Japan but not in the USA for influenza infection [35-39].

Currently, favipiravir is hardly used in clinical practice as it there is not much evidence of efficacy in treating SARS-CoV2. In 2020, Chen et al. conducted a multicenter, prospective, and randomized study of 236 patients (experimental group116 patients, control group - 120 patients). The experimental group was given favipiravir (1600 mg BID on the first day; $600 \mathrm{mg}$ BID from the second day to the end of the experiment). The control group $(N, 120)$ was treated with Arbidol (200 mg TID from the first day to the end of the trial). Routine therapy was also given to both groups. The treatment period for both groups was 7-10 days. The clinical recovery of the patients was considered based on cough relief, oxygen saturation, fever, and respiration rate for $72 \mathrm{~h}$. Patients were also assessed via routine biochemical, urine, nucleic acid, Creactive protein (CRP), and coagulation tests. $\mathrm{CT}$ imaging was also used to assess patient progression. The data supported the therapeutic interventions of favipiravir against SARSCoV-2 but its efficacy needs to be investigated with risk factors like diabetes, CVD, hypertension, obesity, and organ transplantations (kidney and liver). The Chinese registration for this clinical trial is ChiCTR200030254 [40].

\section{Arbidol}

Arbidol (umifenovir) is another anti-viral drug that mitigates the spike protein-ACE-2 interaction. It can decrease the fusion of the SARS virus envelope [40].

\section{Remdesivir}

Remdesivir (formerly GS-5734) is another potential drug against SARS-CoV-2 that is being tested in randomized control trials. It is approved by the USFDA for emergency medicine treatment. Remdesivir and favipiravir act on RdRp to prevent replication and translation processes (Figs. 1 and 2, Table 1). Remdesivir has shown potential in vitro activity against various coronaviruses. Remdesivir was effective during the Ebola virus outbreak as evidenced by the low polymerase activity in host cells and $\mathrm{EC}_{50}$. Its clinical benefits were demonstrated both in Ebola and SARS-CoV-2 patients $[41,42]$. Pharmacokinetics and drug safety were validated in 
clinical trials (single and multiple-dose phase I) and have shown linear kinetics with a half-life of $35 \mathrm{~h}$. The intravenous doses ranging from 3 to $225 \mathrm{mg}$ did not cause any toxicity of the kidney or liver. A single dose of $200 \mathrm{mg}$ and a following dose of $100 \mathrm{mg}$ as a drug regiment are under investigation. The clinical trials (NCT04252664, NCT04280705, NCT 04257656 , NCT04292730, NCT04302766 NCT04292899) of remdesivir are undergoing in mild, moderate, and severe SARS-CoV-2 patients [43].

\section{Other Possible Therapeutic Agents for SARS-CoV-2}

SARS-CoV-2 enters into the host cell with the help of spike proteins by interacting with $\alpha-1$ helix of the ACE- 2 receptor. However, ACE-2 blockers and inhibitors may have adverse effects in DM, hypertension, liver cirrhosis, renal failure, rheumatoid arthritis, and CVD patients because of the receptor localization.

Tocilizumab (TCZ) is a monoclonal antibody against IL-6 currently being used for rheumatoid arthritis, giant cell arteritis, polyarticular juvenile idiopathic arthritis, systemic juvenile idiopathic arthritis, and cytokine release syndrome therapies. The COVID-19 infection causes a cytokine storm (like SARS-CoV and MERS-CoV). Tocilizumab's role in preventing such a storm may have therapeutic advantages against SARS-CoV-2 (Figs. 1 and 2) (Table 1). In 2020, Luo et al. investigated CRP and IL-6 before and after TCZ therapy in COVID-19 patients. All the individuals were separated into moderately, seriously, and critically ill subject groups. The critically and seriously ill patients have comorbidities like DM, hypertension, and stroke. The TCZ was used in combination with methylprednisolone (MP) (used for arthritis) in 8 patients. For 5 patients, TCZ dosage was given BID or more. The dosage concentrations for TCZ were 80-480 mg, and for MP, it was 40-80 mg depending on the severity of COVID-19 infection. Even though TCZ therapy mitigated CRP and IL-6 levels, those who only received a single dose had adverse outcomes. However, the findings from this single-center retrospective study revealed therapeutic advantages of TCZ against SARS-CoV-2 [44]. Another 2020 collateral study by Fu et al. also used TCZ in the treatment of SARS-CoV-2 infection and found it very effective. A TCZ dosage of $400 \mathrm{mg}$ was given to 21 patients and $91 \%$ recovered from respiratory dysfunction. However, this study did not have proper controls [45]. Currently, there are many clinical trials (RCT study NCT04335071; interventional study NCT04317092; NCT04310228) studying therapy of COVID19 via immunomodulatory mechanisms.

Camostat mesylate (acts on transmembrane protease/serine subfamily member 2, TMPRSS2), immunomodulatory molecules such as $\alpha$ - and $\beta$-interferons, dasatinib, baricitinib, cyclosporine, and imatinib, anthelminthic agents (nitazoxanide), and convalescent therapy might have promising therapeutic advantages against SARS-CoV-2 [3]. Sarilumab (IL-6 antagonist) is also under clinical investigation (NCT04315298).

Molecules such as bevacizumab (NCT04275414), eculizumab (NCT04288713), and fingolimod (NCT04280588) are under consideration for COVID-19 therapy. In brief, bevacizumab acts as an anti-vascular endothelial factor, eculizumab functions as an antibody inhibiting terminal complement, and fingolimod is an immunomodulator (approved for multiple sclerosis) [3].

In addition, corticosteroids were also used to decrease inflammatory action in SARS-CoV, MERS-CoV, and influenza infection. Its therapeutic action against SARS-CoV-2 needs to be investigated with and without co-morbidities like DM, hypertension, CVS, renal failure, liver cirrhosis, and stroke.

\section{Vaccines and Their Status}

Vaccines are believed to be the safest approach to protect COVID-19 patients by boosting their own immune system. Developing effective vaccines takes around 12-18 months. Remarkably, developing the monovalent form of H1N1 influenza vaccine from existing trivalent vaccines took only 6 months when this virus was pandemic in 2009 [46, 47]. The vaccines are classified as recombinant protein, RNA, DNA, vector (licensed), and cell culture-based vaccines [28]. When the Ebola virus outbreak occurred in 2014, vesicular stomatitis virus vector-based vaccine was developed, named Ervebo. The recombinant protein vaccine for influenza was developed and licensed by the USA as Flublok. The cell culture-based vaccine, Flucelvax, was developed for influenza virus [47]. These vaccines mimic infectious agents and trigger the production of antibodies by activating B lymphocytes. This immune response is retained in memory cells to combat future infections.

Spike proteins promote viral entry of SARS-CoV-2 into the host cell by interacting with ACE-2 receptors. Antibodies developed against these spike proteins can interfere with this vital interaction and may neutralize the multi-organ effect of SARS-CoV-2. Previously, recombinant protein (for spike proteins), vector-based, and attenuated/inactivated vaccines were developed for SARS-CoV-1 and showed great efficacy (https://clinicaltrials.gov/ct2/show/NCT04261517) [30]. However, a reduced antibody response was seen in reinfected individuals after the primary vaccination. This was attributed to the waning of the humoral immune response over the years [48-52]. Potential vaccines against SARS-CoV-2 have to overcome such issues.

The established findings suggest that SARS-CoV-2 infection causes multi-organ failure (liver, kidney, lungs, and heart) in individuals over the age 50. As a result, vaccines that are developed must not tax the immune systems of the elderly too greatly [53, 54] (Fig. 3 and Table 2). Unfortunately, vaccines 


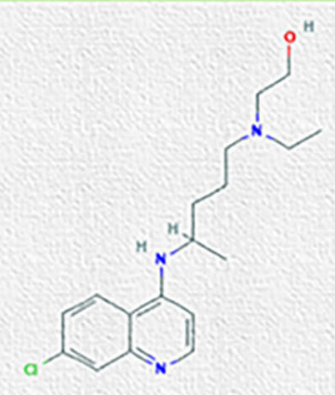

HCQ

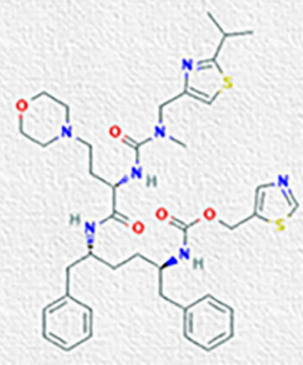

Cobicistat

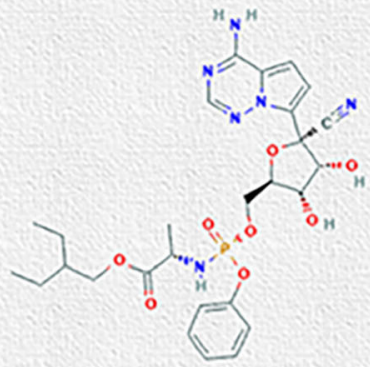

Remdesivir

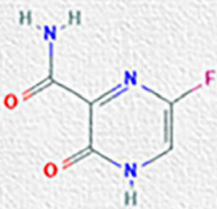

Favipiravir

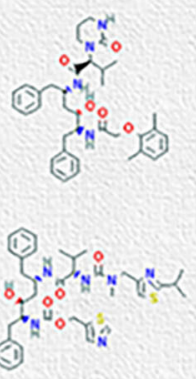

Lopinavir \& Ritonavir

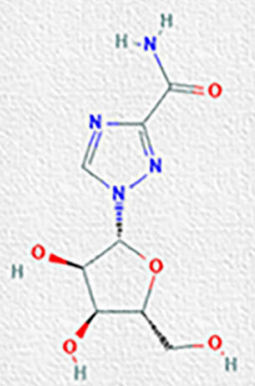

Ribavirin

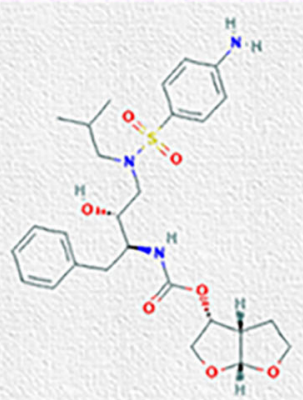

Darunavir

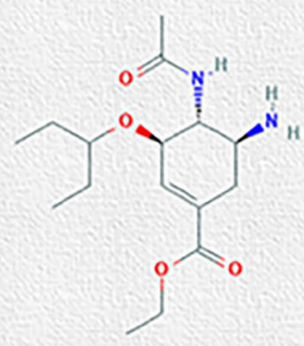

Oseltamivir (Arbidol)

Fig. 3 Structure of drug molecules

in the elderly may not work as effectively as in young individuals because of immune-senescence. Specific IgG/IgM responses of convalescents using a proteome microarray and neutralizing antibodies may serve well as therapeutics [55, 56].

Usually, vaccines undergo three-phase (I, II, III) trials. Phase I trial includes only multiples of 10 (approximately 30-40) individuals and is conducted to check whether the immune response can be seen or not. Upon success, hundreds of individuals will be enrolled in phase II to identify dosage concentrations, immunogenicity, and safety. Finally, thousands of individuals will be enrolled in phase III to measure the efficacy of the vaccine in eliciting an immune response against the disease infection.

There are multiple companies/universities currently doing investigations on developing the SARS-CoV-2 vaccines [57] with the Coalition for Epidemic Preparedness Innovations fund support.

1. mRNA-1273 vaccine entered into phase I clinical trial: it is an encapsulated nano-particle-based mRNA-1273 antigen vaccine developed by Moderna Inc. at NIH research center (ClinicalTrials.gov: NCT04283461). This vaccine is in the phase 2 stage.

2. Codagenix, in collaboration with the Serum Institute of India, is developing a live attenuated vaccine. This vaccine is in the phase 1 stage.

3. Inovio Pharmaceuticals is developing a DNA vaccine focused on spike proteins and it is in phase $2 / 3$ stage
4. NOVAVAX, iBio, Sichuan Clover Biopharmaceuticals, and University of Queensland (GlaxoSmithKline) are focused on developing a recombinant vaccine based on the spike protein. University of Queensland (GlaxoSmithKline) is using a molecular clamp stabilized spike protein. It is in the pre-clinical stage.

5. NOVAVAX has repurposed SARS-CoV vaccines that use full length $\mathrm{S}$ trimers, nanoparticles, and matrix $\mathrm{M}$ to generate antigenicity. This vaccine is in its clinical trial.

6. Institut Pasteur is planning to develop a vaccine against COVID-19 using a replicating viral vector (measles vector). This vaccine is in its pre-clinical stage. Themis/ Univ. of Pittsburg Center for Vaccine Research is also using the same approach in generating the SARS-CoV-2 vaccine.

7. Cansino Biologics and the University of Oxford are developing viral vector-based vaccine for $\mathrm{S}$ proteins. Cansino Biologics vaccines are in phase 2 clinical trials in China and are using adenovirus type 5 as a replication vector.

8. The University of Hong Kong is also developing a vaccine for COVID-19. It is in its pre-clinical stage and human trials may begin in July 2020. The antigen source is unknown.

9. Takis/Applied DNA Sciences/Evvivax and Zydus Cadila are producing DNA vaccines. These vaccines are in the pre-clinical stage.

10. Sinovac Inc. is producing a formaldehyde-inactivated aluminum vaccine that is in its pre-clinical stage 
11. GeoVax/BravoVax C, Janssen Pharmaceutical Companies, Altimmune, Greffex, Tonix Pharma/ Southern Research, Zydus Cadila, and Vaxart are generating non-replicating viral vector vaccines. These vaccines are in the pre-clinical stage.

12. ExpreS2ion (Drosophila S2 insect cell expression system VLPs), WRAIR/USAMRIID (S protein), Clover Biopharmaceuticals Inc./GSK (S trimer), Vaxil Bio (peptide), AJ Vaccines (S protein), Generex/EpiVax (Ii-Key peptide), EpiVax/Univ. of Georgia (S protein), Sanofi Pasteur (S protein by baculovirus), Heat Biologics/Univ. Of Miami (gp-96 backbone), and University of Saskatchewan (adjuvanted microsphere peptide) are producing protein subunit-based vaccines. They are using backbones of S protein, $\mathrm{S}$ trimer, peptide, Ii-Key peptide, and gp-96 to create the vaccine. These vaccines are in the pre-clinical stage.

13. Fudan University/ Shanghai JiaoTong University/ RNACure Biopharma (LNP-encapsulated mRNA cocktail encoding VLP and LNP-encapsulated mRNA encoding RBD), China CDC/Tongji University/ Stermina/Arcturus/Duke-NUS/BioNTech/Fosun Pharma/Pfizer (mRNA), and Imperial College London (SaRNA) are developing RNA vaccines. These vaccines are in the pre-clinical stage.

14. Medicago Inc. is using plant-derived VLP on flu, rotavirus, norovirus, West Nile virus, and cancer platforms to produce a SARS-CoV-2 vaccine. This vaccine is in its pre-clinical stage.

Recently, Zhu et al. (2020) conducted a single-center, open-label, non-randomized phase 1 clinical trial study on tolerability, safety, and immunogenicity Ad5 vector-based COVID-19 vaccine intramuscularly with low $\left(5 \times 10^{10}\right)$, medium $\left(1 \times 10^{11}\right)$, and high $\left(1.5 \times 10^{11}\right)$ viral particles on 109 eligible subjects. The safety of vaccination was assessed on day 28. Specific antibodies, neutralizing antibodies, and T cell responses were measured (with ELISA and flow cytometry). Fifty-four percent vaccine recipients reported pain, whereas $46 \%$ recipients reported fever, fatigue was reported by $44 \%$, headache by $39 \%$, and muscle pain by $17 \%$. However, all these adverse reactions are mild to moderate and to severe in all the dosage groups but there are no severe adverse systemic reactions observed. Specific and neutralizing antibodies were heightened on 14 days of vaccination along with $\mathrm{T}$ cellspecific response but specific and neutralizing antibody response went to maximum peak on 28 days of vaccination. These initial observations strongly warrant further investigations [58]. This study is registered under ClinicalTrials.gov, NCT04313127.

Some companies and universities, such as ImmunoPrecise, MIGAL Galilee Research Institute, Doherty 
Institute, and Tulane University, did not mention the source for their vaccines.

All these different types of vaccines have advantages and disadvantages in the delivery, safety, efficacy, and global production capacity. The negative effect of vector immunity on vaccine efficacy, difficulty in creating infectious clones for live attenuated vaccines, and handling of large amount infectious virus for inactivated vaccines pose a challenge to vaccine development. However, live attenuated (whole virion) and inactivated vaccines (whole virion) are straightforward processed in producing a large number of vaccines and most of the companies follow these two methods. Unfortunately, SARSCoV-2 vaccines may not be available for $12-18$ months. However, they will be helpful for future occurrences of the virus, if it becomes recurrent or seasonal like the flu. Building a herd immunity is crucial in the fight against SARS-CoV-2. Around $71-74 \%$ of the population must buy into these vaccine programs in order to develop the herd immunity. However, among the global shutdown and animosity towards healthcare systems, many people are less inclined to be vaccinated. Only 73.9\% of 7664 participants from 7 European nations would be willing to get vaccinated when a vaccine comes into the market. What is even more troubling is that younger populations, between the ages of 18-24, were less willing to receive vaccines than the elderly [59]. These figures are troubling and reveal an underlying problem within the healthcare system that has been brought to light by the COVID-19 pandemic.

\section{Conclusions and Future Directions}

The COVID-19 created a health emergency that the world was not prepared for. Physicians had to repurpose previous drugs to supplement the standard medical management to maximize health outcomes. However, these results were not satisfactory in COVID-19 patients with DM, hypertension, CVS, renal failure, liver cirrhosis, stroke, and other co-morbidities. Currently, USFDA has approved HCQ and remdesivir, but current reports are controversial on patients with co-morbidities. A few physicians have repurposed Ebola, SARS-CoV, MERS-CoV, and HIV drugs to eradicate SARS-CoV-2 infection. IL-6 and convalescent therapy are also used in the clinical management of the disease. This article summarizes both the breadth of opportunities and the striking lack of knowledge on drug mechanisms, efficacy, and outcomes. Especially during the COVID-19 health crisis, further investigation into the repurposing of drugs, identification of novel targets, and development of vaccines need to be prioritized in order to save lives.
Funding Information Authors thank DBT for awarding Ramalingaswami Re-entry Fellowship to RK. Authors also thank NIH for supporting PHR with the following grants: R01AG042178, R01AG47812, R01NS105473, and AG060767.

\section{Compliance with Ethical Standards}

Conflict of Interest The authors declare that they have no conflict of interest.

\section{References}

1. Li Q, Guan X, Wu P, Wang X, Zhou L, Tong Y, Ren R, Leung KSM et al (2020) Early transmission dynamics in Wuhan, China, of novel coronavirus-infected pneumonia. N Engl J Med 382:11991207

2. Xiao Y, Pan H, She Q, Wang F, Chen M (2020) Prevention of SARS-CoV-2 infection in patients with decompensated cirrhosis. Lancet Gastroenterol Hepatol 5:528-529

3. Sanders JM, Monogue ML, Jodlowski TZ, Cutrell JB (2020) Pharmacologic treatments for coronavirus disease 2019 (COVID19): a review. JAMA. 323(1824):1836. https://doi.org/10.1001/ jama.2020.6019

4. Wu A, Peng Y, Huang B et al (2020) Genome composition and divergence of the novel coronavirus (2019-nCoV) originating in China. Cell Host Microbe 27(325):328

5. Andersen KG, Rambaut A, Lipkin WI, Holmes EC, Garry RF (2020) The proximal origin of SARS-CoV-2. Nat Med 26:450-452

6. Lotteau V, Teyton L, Peleraux A, Nilsson T, Karlsson L, Schmid SL, Quaranta V, Peterson PA (1990) Intracellular transport of class II MHC molecules directed by invariant chain. Nature 348:600-605

7. Wu SF, Chang CB, Hsu JM, Lu MC, Lai NS, Li C, Tung CH (2017) Hydroxychloroquine inhibits CD154 expression in CD4(+ ) T lymphocytes of systemic lupus erythematosus through NFAT, but not STAT5, signaling. Arthritis Res Ther 19:183

8. van den Borne BE, Dijkmans BA, de Rooij HH, le Cessie S, Verweij CL (1997) Chloroquineand hydroxychloroquine equally affect tumor necrosis factor-alpha interleukin 6, and interferongamma production by peripheral blood mononuclear cells. J Rheumatol 24:55-60

9. Kuznik A, Bencina M, Svajger U, Jeras M, Rozman B, Jerala R (2011) Mechanism of endosomal TLR inhibition by antimalarial drugs and imidazoquinolines. J Immunol (Baltimore, Md : 1950) 186:4794-4804

10. Ewald SE, Lee BL, Lau L, Wickliffe KE, Shi GP, Chapman HA, Barton GM (2008) The ectodomain of Toll-like receptor 9 is cleaved to generate a functional receptor. Nature 456:658-662

11. Häcker H, Mischak H, Miethke T, Liptay S, Schmid R, Sparwasser T, Heeg K, Lipford GB et al (1998) CpG-DNA-specific activation of antigen presenting cells requires stress kinase activity and is preceded by non-specific endocytosis and endosomal maturation. EMBO J 17:6230-6240

12. Vollmer J, Tluk S, Schmitz C et al (2005) Immune stimulation mediated by autoantigen binding sites within small nuclear RNAs involves Toll-like receptors 7 and 8. J Exp Med 202:1575-1585

13. An J, Woodward JJ, Sasaki T, Minie M, Elkon KB (2015) Cutting edge: antimalarial drugs inhibit IFN- $\beta$ production through blockade of cyclic GMP-AMP synthase DNA interaction. J Immunol (Baltimore, Md : 1950) 194:4089-4093

14. Zhou D, Dai SM, Tong Q (2020) COVID-19: a recommendation to examine the effect of hydroxychloroquine in preventing infection and progression. The Journal of antimicrobial chemotherapy. J 
Antimicrob Chemother:dkaa114. https://doi.org/10.1093/jac/ dkaa114

15. Devaux CA, Rolain JM, Colson P, Raoult D (2020) New insights on the antiviral effects of chloroquine against coronavirus: what to expect for COVID-19? Int J Antimicrob Agents 55:105938

16. Gao J, Tian Z, Yang X (2020) Breakthrough: chloroquine phosphate has shown apparent efficacy in treatment of COVID-19 associated pneumonia in clinical studies. Biosci Trends 14:72-73

17. Gautret P, Lagier JC, Parola P et al (2020) Hydroxychloroquine and azithromycin as a treatment of COVID-19: results of an open-label non-randomized clinical trial. Int J Antimicrob Agents:105949

18. Chen J, Liu D, Liu L et al (2020) A pilot study of hydroxychloroquine in treatment of patients with moderate COVID-19. Zhejiang da xue xue bao Yi xue ban = J Zhejiang Univ Med Sci 49:215-219

19. Lenzer J (2020) Covid-19: US gives emergency approval to hydroxychloroquine despite lack of evidence. BMJ 369:m1335 Published 2020. https://doi.org/10.1136/bmj.m1335

20. Yi SG, Rogers AW, Saharia A, et al Early experience with COVID19 and solid organ transplantation at a US high-volume transplant center [published online ahead of print, 2020 Jun 1]. Transplantation. 2020; https://doi.org/10.1097/TP. 0000000000003339

21. Yao X, Ye F, Zhang M, et al (2020) In vitro antiviral activity and projection of optimized dosing design of hydroxychloroquine for the treatment of severe acute respiratory syndrome coronavirus 2 (SARS-CoV-2). [published online ahead of print, 2020 Mar 9]. Clin Infect Dis. ciaa237. https://doi.org/10.1093/cid/ciaa237

22. Kalil AC (2020) Treating COVID-19-off-label drug use, compassionate use, and randomized clinical trials during pandemics. JAMA 323:1897. https://doi.org/10.1001/jama.2020.4742

23. Interview with David Juurlink (2020) Coronavirus (COVID-19) update: chloroquine/hydroxychloroquine and azithromycin. JAMA March 24, 2020. Accessed 5 Apr 2020. https://edhub.amaassn.org/jn-learning/audioplayer/18337225

24. Osadchy A, Ratnapalan T, Koren G (2011) Ocular toxicity in children exposed in utero to antimalarial drugs: review of the literature. J Rheumatol 38:2504-2508

25. Borba MGS, Val FFA, Sampaio VS, Alexandre MAA, Melo GC, Brito M, Mourão MPG, Brito-Sousa JD et al (2020) Effect of high vs low doses of chloroquine diphosphate as adjunctive therapy for patients hospitalized with severe acute respiratory syndrome coronavirus 2 (SARS-CoV-2) infection: a randomized clinical trial. JAMA Netw Open 3:e208857

26. Stockman LJ, Bellamy R, Garner P (2006) SARS: systematic review of treatment effects. PLoS Med 3:e343

27. Chu CM, Cheng VC, Hung IF, Wong MM, Chan KH, Chan KS, Kao RY, Poon LL et al (2004) Role of lopinavir/ritonavir in the treatment of SARS: initial virological and clinical findings. Thorax 59:252-256

28. de Wilde AH, Jochmans D, Posthuma CC, Zevenhoven-Dobbe JC, van Nieuwkoop S, Bestebroer TM, van den Hoogen BG, Neyts J et al (2014) Screening of an FDAapproved compound library identifies four small-molecule inhibitors of Middle East respiratory syndrome coronavirus replication in cell culture. Antimicrob Agents Chemother 58:4875-4884

29. Yao TT, Qian JD, Zhu WY, Wang Y, Wang GQ (2020) A systematic review of lopinavir therapy for SARS coronavirus and MERS coronavirus-a possible reference for coronavirus disease-19 treatment option. J Med Virol 92:556-563

30. Chan KS, Lai ST, Chu CM et al (2003) Treatment of severe acute respiratory syndrome with lopinavir/ritonavir: a multicentre retrospective matched cohort study. Hong Kong Medical Journal = Xianggang yi xue za zhi 9:399-406
31. Cao B, Wang Y, Wen D, Liu W, Wang J, Fan G, Ruan L, Song B et al (2020) A trial of lopinavir-ritonavir in adults hospitalized with severe Covid-19. N Engl J Med 382:1787-1799

32. De Meyer S, Bojkova D, Cinati J, et al (2020) Lack of antiviral activity of darunavir against SARS-CoV-2. medRxiv 2020: 2020.04.03.20052548

33. https://www.who.int/blueprint/priority-diseases/key action/Table of therapeutics_Appendix_17022020.pdf (accessed on 28 May 2020)

34. Wang M, Cao R, Zhang L et al (2020) Remdesivir and chloroquine effectively inhibit the recently emerged novel coronavirus (2019$\mathrm{nCoV}$ ) in vitro. Cell Res 30:26971

35. Mentre F, Taburet AM, Guedj J, Anglaret X, Keita S, de Lamballerie X, Malvy D (2015) Dose regimen of favipiravir for Ebola virus disease. Lancet Infect Dis 15:150-151

36. Sissoko D, Laouenan C, Folkesson E, M'Lebing AB, Beavogui AH, Baize S, Camara AM, Maes P et al (2016) Experimental treatment with favipiravir for Ebola virus disease (the JIKI trial): a historically controlled, single-arm proof of-concept trial in Guinea. PLoS Med 13:e1001967

37. Shiraki K, Daikoku T (2020) Favipiravir, an anti-influenza drug against life threatening RNA virus infections. Pharmacol Ther 209:107512

38. Chinello P, Petrosillo N, Pittalis S, Biava G, Ippolito G, Nicastri E (2017) QTc interval prolongation during favipiravir therapy in an Ebolavirus-infected patient. PLoS Negl Trop Dis 11:e006034

39. Kumagai Y, Murakawa Y, Hasunuma T, Aso M, Yuji W, Sakurai T, Noto M, Oe T et al (2015) Lack of effect of favipiravir, a novel antiviral agent, on QT interval in healthy Japanese adults. Int J Clin Pharmacol Ther 53:866-874

40. Chen C, Zhang Y, Huang J, et al (2020) Favipiravir versus Arbidol for COVID-19: a randomized clinical trial. medRxiv 2020.03.17.20037432

41. Siegel D, Hui HC, Doerffler E, Clarke MO, Chun K, Zhang L, Neville S, Carra E et al (2017) Discovery and synthesis of a phosphoramidate prodrug of a pyrrolo[2,1-f][triazin-4-amino] adenine C-nucleoside (GS-5734) for the treatment of Ebola and emerging viruses. J Med Chem 60:1648-1661

42. Al-Tawfiq JA, Al-Homoud AH, Memish ZA (2020) Remdesivir as a possible therapeutic option for the COVID-19. Travel Med Infect Dis 2020:101615

43. World Health Organization (2018) WHO R\&D blueprint: ad-hoc expert consultation on clinical trials for Ebola therapeutics. Published October 2018. Accessed 20 May 2020. https://www. who.int/ebola/drc-2018/summaries-of-evidence experimentaltherapeutics.pdf

44. Luo P, Liu Y, Qiu L, Liu X, Liu D, Li J (2020) Tocilizumab treatment in COVID-19: a single center experience. J Med Virol 92:814-818. https://doi.org/10.1002/jmv.25801

45. Fu B, Xu X, Wei H (2020) Why tocilizumab could be an effective treatment for severe COVID-19? J Transl Med 18:164

46. Krammer F, Palese P (2015) Advances in the development of influenza virus vaccines. Nat Rev Drug Discov 14:167-182

47. Amanat F, Krammer F (2020) SARS-CoV-2 vaccines: status report. Immunity 52:583-589

48. Wu F, Zhao S, Yu B, Chen YM, Wang W, Song ZG, Hu Y, Tao $\mathrm{ZW}$ et al (2020) A new coronavirus associated with human respiratory disease in China. Nature 579:265-269

49. Zhou P, Yang XL, Wang XG, Hu B, Zhang L, Zhang W, Si HR, Zhu Y et al (2020) A pneumonia outbreak associated with a new coronavirus of probable bat origin. Nature 579:270-273

50. Zhu N, Zhang D, Wang W, Li X, Yang B, Song J, Zhao X, Huang $\mathrm{B}$ et al (2020) A novel coronavirus from patients with pneumonia in China, 2019. N Engl J Med 382:727-733 
51. Lan J, Ge J, Yu J, Shan S, Zhou H, Fan S, Zhang Q, Shi X et al (2020) Structure of the SARS-CoV-2 spike receptor-binding domain bound to the ACE2 receptor. Nature. 581:215-220

52. Wrapp D, Wang N, Corbett KS, Goldsmith JA, Hsieh CL, Abiona O, Graham BS, McLellan JS (2020) Cryo-EM structure of the 2019-nCoV spike in the prefusion conformation. Science 367: $1260-1263$

53. Lan L, Xu D, Ye G, Xia C, Wang S, Li Y, Xu H (2020) Positive RT-PCR test results in patients recovered from COVID-19. JAMA. 323:1502-1503

54. Callow KA, Parry HF, Sergeant M, Tyrrell DA (1990) The time course of the immune response to experimental coronavirus infection of man. Epidemiol Infect 105:435-446

55. Jiang H-W, Li Y, Zhang H-N, et al (2020) Global profiling of SARS-CoV-2 specific IgG/IgM responses of convalescents using a proteome microarray. medRxiv 2020: 2020.03.20.20039495

56. Wu F, Wang A, Liu M, et al (2020) Neutralizing antibody responses to SARS-CoV-2 in a COVID-19 recovered patient cohort and their implications. medRxiv 2020: 2020.03.30.20047365
57. https://www.who.int/blueprint/priority-diseases/key-action/novelcoronavirus landscapencov.pdf?ua=1 (accessed on May $28^{\text {th }}, 2020$ )

58. Zhu FC, Li YH, Guan XH et al $(2020,2020)$ Safety, tolerability, and immunogenicity of a recombinant adenovirus type- 5 vectored COVID-19 vaccine: a dose-escalation, open label, non-randomised, first-in-human trial. Lancet (London, England). https://doi.org/10. 1016/S0140-6736(20)31208-3

59. Neumann-Böhme S, Varghese NE, Sabat I, Barros PP, Brouwer W, van Exel J, Schreyögg J, Stargardt T (2020) Once we have it, will we use it? A European survey on willingness to be vaccinated against COVID-19 [published online ahead of print, 2020 Jun 26]. Eur J Health Econ:1-6. https://doi.org/10.1007/s10198020-01208-6

Publisher's Note Springer Nature remains neutral with regard to jurisdictional claims in published maps and institutional affiliations. 